\title{
The organization and consequences of eicosanoid signaling
}

\author{
Roy J. Soberman and Peter Christmas \\ Renal Unit and Department of Medicine, Massachusetts General Hospital, Harvard Medical School, Charlestown, Massachusetts, USA \\ J. Clin. Invest. 111:1107-1113 (2003). doi:10.1172/JCI200318338.
}

\section{Organization of leukotriene and prostaglandin synthesis}

As described in the introduction to this Perspective series (1), signaling by arachidonic acid represents a paradigm for the use of oxygen in the transmission of information. At the same time, arachidonic acid signaling can also contribute to the propagation of cellular damage. This duality is typified by a signaling cascade that (a) prevents the activation of 5-lipoxygenase (5-LO) in resting cells and (b) results in the formation and release of leukotrienes (LTs), which requires the sequential activation and interaction of at least eight different proteins. In fact, all lipoxygenases require membrane translocation to exert activity. In the case of the formation of COX products, particularly prostaglandin $\mathrm{E}_{2}\left(\mathrm{PGE}_{2}\right)$ and $\mathrm{PGD}_{2}$, humans have evolved two sets of biosynthetic enzymes that differ not only in their cell- and tissue-specific localization, but also in their subcellular localization and requirement for reduced glutathione, a cellular defense against oxidative damage. This review will focus on three aspects of arachidonic acid biology. First, the compartmentalization and organization of eicosanoid synthesis, specifically LTs and PGs, will be discussed. This will illustrate the elaborate mechanisms that keep unwanted lipoxygenation at arm's length and also show that the enzymes such as glutathione-Stransferases, epoxide hydrolases, and carrier proteins that are commonly thought of as biosynthetic also belong to families that are generally considered to play a role in detoxification. Second, the potential cellular oxidative damage that is produced as a by-product of the use of oxygen and lipid substrates is examined. Finally, mechanisms that are used to amplify signaling diversity from a core of LTs and PGs are discussed.

\footnotetext{
Address correspondence to: Roy J. Soberman, Renal Unit and Department of Medicine, Massachusetts General Hospital, Harvard Medical School, 149 Navy Yard, Charlestown, Massachusetts 02129, USA. Phone: (617) 726-3747; Fax: (617) 726-5669; E-mail: Soberman@helix.mgh.harvard.edu. Conflict of interest: The authors have declared that no conflict of interest exists.

Nonstandard abbreviations used: 5-lipoxygenase (5-LO); leukotriene (LT); cytoplasmic phospholipase $\mathrm{A}_{2}\left(\mathrm{CPLA}_{2}\right)$; 5(S)-hydroxy,6-trans-8,11,14-cis-eicosatetraenoic acid (5-HPETE); 5-lipoxygenase-activating protein (FLAP); multidrugresistance protein 1 (MRP1); reactive oxygen species (ROS); membrane-associated proteins in eicosanoid and glutathione metabolism (MAPEG); glutathione-S-transferase 2 (GST2); microsomal prostaglandin $\mathrm{E}_{2}$ synthase-1 (mPGES-1); epoxyeicosatrienoic acid (EET).
}

The role of leukotrienes $C_{4}$ and $D_{4}$ in disease LTs are the products of the 5-LO pathway of arachidonic acid metabolism (Figure 1). The initial interest in LTs followed largely from their association with the pathogenesis of asthma (2). $\mathrm{LTC}_{4}$, identified as the parent molecule of the sulfidopeptide LTs, is generated from eosinophils and mast cells in large amounts, and also from monocytes and macrophages (2-7). However, it is not formed by polymorphonuclear leukocytes $(2-5)$. When released from cells, $\mathrm{LTC}_{4}$ is converted to $\mathrm{LTD}_{4}$ (2-7), and both exert their biological effects via $G$ protein-coupled receptors $(8,9)$. $\mathrm{LTD}_{4}$ and $\mathrm{LTC}_{4}$ cause the constriction of smooth muscle, and the clinical correlate is bronchial smooth muscle constriction in asthma (2, $10,11)$. The role of $\mathrm{LTD}_{4}$ as a major contributor to asthmatic bronchospasm has been firmly established, and aerosolized $\mathrm{LTD}_{4}$ and $\mathrm{LTC}_{4}$ cause bronchospasm when taken by inhaler $(10,11)$. The metabolic product of $\mathrm{LTD}_{4}$, 5(S)-hydroxy, 6(R)-cysteinyl-7,9,11-trans,14-cis-eicosatetraenoic acid, $\left(\mathrm{LTE}_{4}\right)$, has been found at high levels in the serum and urine of patients with asthma and allergic rhinitis (12). When cold-induced bronchoconstriction, allergen-induced asthma, and exercise-induced asthma were analyzed, antagonists of the 5-LO pathway were able to alleviate bronchospasm (13-17). Pretreatment with the $\mathrm{LTD}_{4}$ receptor antagonist MK-0476 has been shown to block the bronchoconstrictive response to all forms of challenge and alleviate ongoing brochoconstriction (16). The use of $\mathrm{LTD}_{4}$ receptor and 5-LO antagonists has also blocked the severity and occurrence of asthmatic attacks in clinical trials, and these agents are particularly effective in chronic mild asthma, for which they are recommended for clinical use (18-23). LTs are also considered to be central to the pathogenesis of allergic rhinitis, in which cells expressing the cysteinyl LT1 receptor are highly expressed in $\mathrm{CD}^{4} 5^{+}$nasal leukocytes, and recent studies have shown that cysteinyl LTs regulate the trafficking of $T$ cells in vivo $(24,25)$. Subsequently, $\mathrm{LTD}_{4}$ receptor antagonists have proved to constitute an effective therapeutic modality for this disorder. Knockout animals that lack LTC $_{4}$ synthase have markedly attenuated vascular responses that are dependent on IgE-mediated $\mathrm{LTC}_{4}$ release (26).

As described above, $\mathrm{LTD}_{4}$ and $\mathrm{LTC}_{4}$ have been shown to function via both high- and low-affinity $G$ protein-coupled receptors $(8,9,27,28)$, and these receptors are present on human eosinophils and monocytes, 


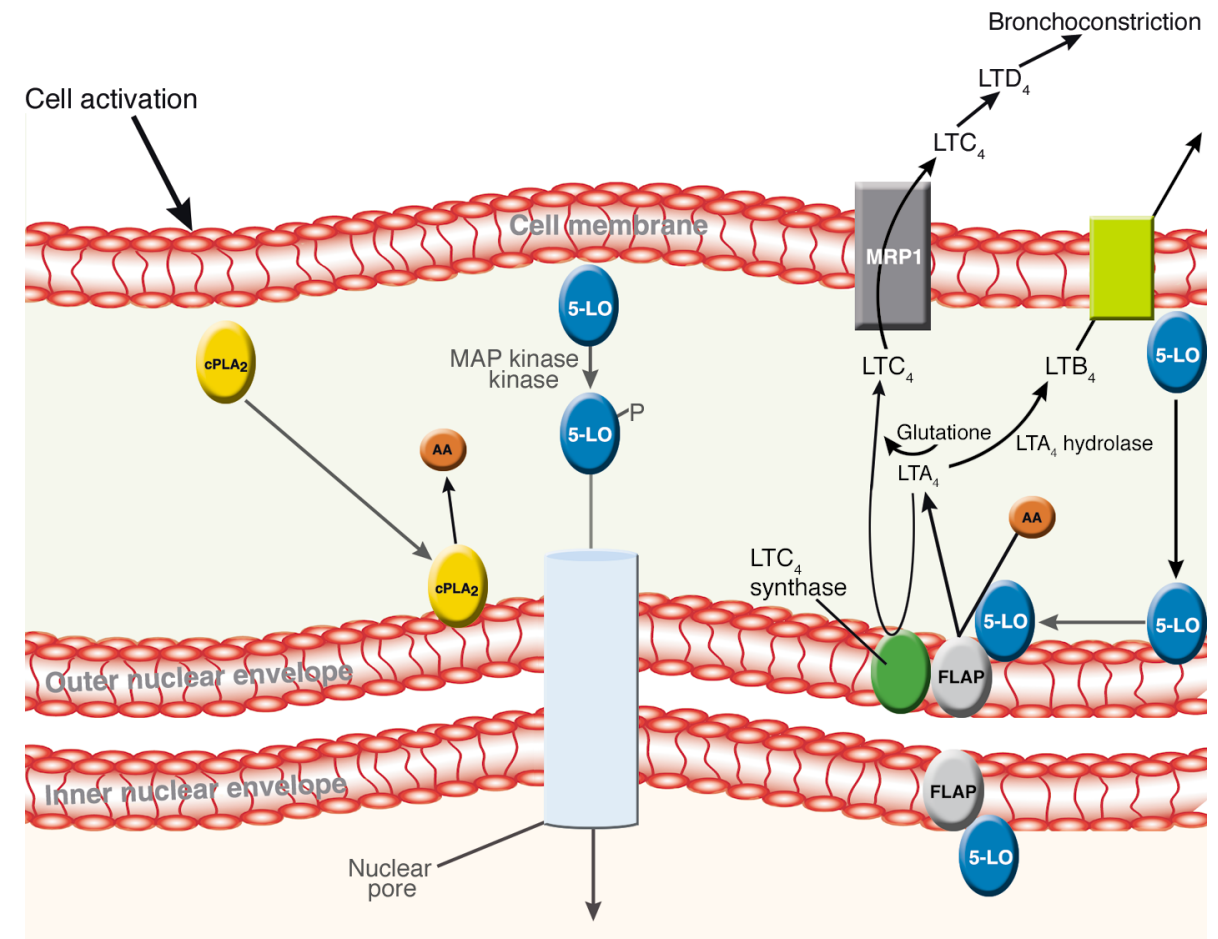

\section{Figure 1}

LT biosynthesis and assembly. Upon cellular activation of a mast cell or macrophage by IgE-antigen complexes or other stimuli, a cascade of cell activation events results in LT biosynthesis. A concomitant rise in free calcium induces translocation of cPLA 2 to intracellular membranes, where it releases arachidonic acid. In parallel, 5-LO is phosphorylated by MAP kinase kinase and traffics through the nuclear pore to the nucleus (possibly in association with NF-KB) or directly to the outer nuclear envelope. 5-LO then associates with the nuclear membrane, and possibly with FLAP. FLAP facilitates arachidonic acid presentation to 5-LO and subsequent conversion of arachidonic acid to LTA $_{4}$. LTA interacts $_{4}$ with $\mathrm{LTA}_{4}$ hydrolase to form $\mathrm{LTB}_{4}$, or with $\mathrm{LTC}_{4}$ synthase to form $\mathrm{LTC}_{4}$. The synthesis of $L T s A_{4}$, $B_{4}$, and $C_{4}$ probably takes place within the lumen of, or in close proximity to, the nuclear membranes. However, for clarity they are shown here throughout the cytosol. FLAP is present on both the inner and the outer nuclear envelope, but LTC 4 synthase is exclusively expressed on the outer nuclear membrane and ER.

where they function in chemotaxis and cell activation. Thus, insight into the cellular mechanisms that regulate the enzymatic interactions during LT biosynthesis represents a critical step in our understanding of the formation and activity of these molecules in both health and disease.

\section{Cellular and molecular biology of LT biosynthesis}

The formation of LTs is initiated when eosinophils, mast cells, polymorphonuclear leukocytes, or monocytes are activated to release arachidonic acid. This occurs after the translocation of the $86-\mathrm{kDa}$ calciumdependent cytoplasmic phospholipase $\mathrm{A}_{2}\left(\mathrm{cPLA}_{2}\right)$ to the nuclear envelope, ER, or Golgi apparatus (Figure 1) (29). 5-LO is also translocated to the nuclear envelope (30-32) and acts on arachidonic acid in sequential steps to generate 5(S)-hydroxy,6-trans-8,11,14-ciseicosatetraenoic acid (5-HPETE) and then 5(S),6(R)oxo-7,9,11-trans-14-cis-eicosatetraenoic acid, $\left(\mathrm{LTA}_{4}\right)$ (33). Within cells, these enzymatic steps require the expression of the $17-\mathrm{kDa}$ nuclear envelope protein 5 -LO-activating protein (FLAP). FLAP is critical to cellular 5-LO activity and to its membrane interactions, but not to 5 -LO translocation $(34,35)$. It has been postulated that FLAP presents arachidonic acid to 5-LO (36) but may also restrict the diffusion of arachidonic acid through cellular membranes. FLAP may also "dock" 5-LO to its membrane target after translocation. $\mathrm{LTA}_{4}$ is then converted to $\mathrm{LTB}_{4}$ by the action of the enzyme $\mathrm{LTA}_{4}$ hydrolase (37) (Figure 1). Once formed, $\mathrm{LTB}_{4}$ is exported from cells by an active process (38) and exerts its effects on other phagocytic cells via high- or low-affinity $G$ protein-coupled receptors $(39,40)$. Alternatively, in eosinophils, monocytes, and mast cells, $\mathrm{LTA}_{4}$ is conjugated with reduced glutathione to form $\mathrm{LTC}_{4}$. This reaction is catalyzed by the enzyme $\mathrm{LTC}_{4}$ synthase, a $17-\mathrm{kDa}$ protein also located in the ER and outer nuclear membrane (41-44). LTC $_{4}$ is exported from cells by the multidrug-resistance protein 1 (MRP1) and then metabolized by $\mathrm{LTD}_{4}$, which plays a subsequent role in the induction of bronchoconstriction and edema (45-47). MRP1 knockout animals are characterized by intracellular retention of $\mathrm{LTC}_{4}$ and significant asthmatic responses to allergen challenge (48), and dendritic cells from these animals are deficient in trafficking under certain circumstances (49). As described above, the fact that the enzymes commonly 
thought of as biosynthetic belong to families that are generally considered to play a role in detoxification raises the intriguing possibility that LT signaling may have evolved as an adaptive response to oxidative stress.

LT formation is regulated by compartmentalization The generation of LTs and PGs is under a complex set of controls. As exemplified in mast cells, the synthesis of LTs and PGs is initiated by $\mathrm{CPLA}_{2}$, which is specific for phospholipids that contain arachidonic acid in the SN2 position (50). The enzyme is calcium-dependent and is translocated to the nuclear membrane in rat basophilic leukemia cells stimulated with IgE or calcium ionophore A23187 (29). This translocation is required for cellular activity and is mediated by a phospholipid-binding domain (51). Phosphorylation by MAPK at S505 can augment activity three- to fourfold but is not required for membrane association (52-55). The central role of $\mathrm{CPLA}_{2}$ in LT production has been confirmed by studies using peritoneal macrophages prepared from $\mathrm{CPLA}_{2}$ knockout mice (56). These cells produce no LTs in response to cell activation with calcium ionophore A23187. The enzyme is also found to localize within the cytosol of resting cells in this system. However, in other systems, detailed studies have shown that $\mathrm{CPLA}_{2}$ traffics to the Golgi apparatus (57). This implies that arachidonic acid can be rapidly moved to the ER and nuclear envelope, where it can subsequently interact with FLAP and 5-LO.

5-LO is phosphorylated concomitantly with translocation to the nucleus and nuclear envelope (58-60). Phosphorylation via MAPK-activated protein kinase-2 is critical in controlling targeting and activation of this enzyme (61). A second critical aspect of 5-LO control may be its interaction with the p 65 subunit of NF-кB (62). Whether 5-LO activation can modify the activity of $\mathrm{NF}-\kappa \mathrm{B}$ remains to be determined, though this has been suggested to occur via 5-LO-mediated generation of reactive oxygen species (ROS) (63). 5-LO has a functional C2-like domain, which is important in mediating its membrane interactions, specifically with phosphatidyl choline (64). Recent studies have also shown that $\mathrm{LTA}_{4}$ hydrolase is translocated to the nucleus upon stimulation of rat basophilic leukemia cells (65), but not in human peripheral blood leukocytes. This would place the site of $\mathrm{LTB}_{4}$ synthesis within the nucleus of rat basophilic leukemia cells, a site where $\mathrm{LTB}_{4}$ has been suggested to function as a ligand for $\operatorname{PPAR} \alpha(66)$.

\section{FLAP, LTC $_{4}$ synthase, and $\mathrm{LTC}_{4}$ generation: the compartmentalization of $\mathrm{LTC}_{4}$ and $\mathrm{LTB}_{4}$ biosynthesis}

Both sides of the nuclear envelope are potential sites of LT formation, and the interactions between the enzymes mediating LT biosynthesis at the membrane interface ultimately determine the fate of $\mathrm{LTA}_{4}$ and the regulation of $\mathrm{LTC}_{4}$ synthesis (30-32, 34-36, 67-71). As described above, the two proteins that regulate the synthesis of $\mathrm{LTC}_{4}$ in bone marrow-derived cells are FLAP and $\mathrm{LTC}_{4}$ synthase. These proteins are members of the superfamily known as membrane-associated proteins in eicosanoid and glutathione metabolism (MAPEG). This family is composed of six members that are central to the synthesis of LTs and PGs. MAPEG proteins are $17-\mathrm{kDa}$ integral membrane proteins with three transmembrane domains and high structural identity. Three MAPEG proteins, FLAP, LTC $_{4}$ synthase, and microsomal glutathione- $S$-transferase 2 (GST2) (72), control the synthesis of $\mathrm{LTC}_{4}$ and $\mathrm{LTB}_{4}$. A fourth member of the MAPEG family, inducible microsomal prostaglandin $\mathrm{E}_{2}$ synthase (mPGES-1), regulates the formation of $\mathrm{PGE}_{2}$ in inflammatory settings (73-76). Very little is known about the regulation of these MAPEG proteins, but it is becoming increasingly clear that their membrane interactions may play a critical role in their regulation.

Figure 2 illustrates the topological relationships of the membrane domains of LTC $_{4}$ synthase as recently determined by our group (44), in addition to the likely orientation of FLAP and the topology of both COX1 and COX2 (77). Within transmembrane domains 1 and 3, LTC $_{4}$ synthase and FLAP share 52\% identity between amino acids 41 and 97 of FLAP and between amino acids 45 and 101 of LTC $_{4}$ synthase (32-36, 42). LTC 4 synthase and microsomal GST2 share an even higher identity within this region. FLAP, characterized by three hydrophobic regions, has been localized to the nuclear envelope in polymorphonuclear leukocytes and monocytes, and the lipid-binding moiety is contained within the first hydrophilic loop (36). Immunoelectron microscopy of FLAP, using antibody to the first hydrophilic loop, has shown that FLAP is preferentially localized to the inner nuclear membrane, with the lipid-binding site oriented to the lumen (32).

$\mathrm{LTC}_{4}$ synthase has recently been found to localize to the ER and outer nuclear membrane (44). However, in contrast to FLAP, it is excluded from the inner nuclear membrane. Similar to FLAP, LTC $_{4}$ has its active site localized to the ER lumen.

These results, combined with the observation that $\mathrm{LTA}_{4}$ hydrolase translocates to the nucleus, indicate that in certain settings, the synthesis of $\mathrm{LTB}_{4}$ and $\mathrm{LTC}_{4}$ is compartmentalized. The molecular mechanism by which LTC $_{4}$ synthase and FLAP are segregated between the inner and outer nuclear membrane is one basis for

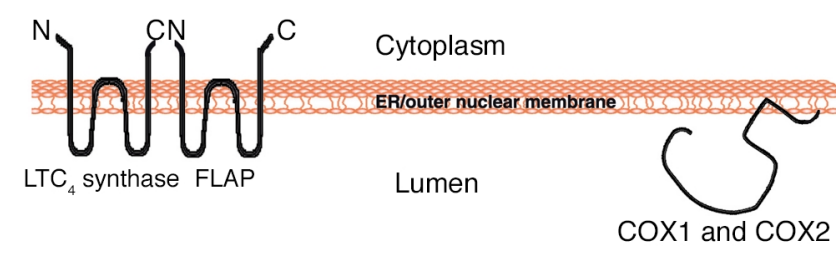

Figure 2

Membrane topology of proteins involved in eicosanoid synthesis. The active sites of $\mathrm{LTC}_{4}$ synthase, COX1, COX2, and the lipid-binding domain of FLAP are all oriented to the lumen of the ER and the nuclear envelope. 
the compartmentalized synthesis of $\mathrm{LTB}_{4}$ and $\mathrm{LTC}_{4}$, but the molecular basis for the compartmentalization of the latter two proteins remains unknown.

Recent studies of $\mathrm{PGE}_{2}$ biosynthesis emphasize that an understanding of the membrane interactions of MAPEG proteins is central to an understanding of their biological role and suggest that regulated protein interactions may be important to their biological activity. PGES2 is coinduced and functionally coupled with $\mathrm{COX} 2$ in inflammatory settings, whereas cytosolic $\mathrm{PGE}_{2}$ synthase 1 is coupled to COX1 (73-77). How COX2 and mPGES-1 interact is not known, but three possible mechanisms have been proposed (73-77). First, direct passage of $\mathrm{PGH}_{2}$ between COX2 and mPGES-1 may occur, indicating that specific interactions between proteins of eicosanoid biosynthesis are critical to the efficient formation of $\mathrm{PGE}_{2}$. Alternatively, the association of COX2 and mPGES-1 may simply be kinetically favored. Finally, differential membrane compartmentalization has also been postulated to play a role.

Because the formation of $\mathrm{LTC}_{4}$ is controlled by two members of the MAPEG family (FLAP and $\mathrm{LTC}_{4}$ synthase), a critical question in understanding the intracellular biology of LT formation should be raised: Do the biosynthetic enzymes of LT formation interact with each other? Two possible models can be proposed. In one, a multiprotein complex is formed that mediates the efficient transfer of $\mathrm{LTA}_{4}$ to $\mathrm{LTC}_{4}$ synthase. This would have the advantage of preventing oxidative damage secondary to the formation of $\mathrm{LTA}_{4}$ adducts. In a second model, all the proteins are independent, and $\mathrm{LTA}_{4}$ passes between them and is captured by individual molecules. Evidence supports the existence of at least some protein interactions. As described above, 5-LO is targeted to the nuclear envelope. This interaction is partly dependent on FLAP, and cells that lack FLAP or are treated with the FLAP inhibitor MK-886 do not synthesize LTs and have deficient targeting of 5-LO to nuclear membranes $(34,78)$. Direct interactions between 5-LO and FLAP have been postulated, but not demonstrated; however, this may be secondary to the technology employed. An ability of FLAP and $\mathrm{LTC}_{4}$ synthase to form heterodimers would imply that interactions between MAPEG proteins are critical in controlling the formation of LTs. The situation is made more complex by the fact that both COXs and $\mathrm{LTC}_{4}$ synthase are known to form homodimers (77).

An additional important protein interaction occurs between PKC and LTC $_{4}$ synthase. Pretreatment of cells with the activator of PKC, phorbol myristate acetate, inhibits subsequent $\mathrm{LTC}_{4}$ formation by up to $70 \%$ (79-82), suggesting another potential interaction on the outer nuclear envelope. This interaction has not been directly demonstrated, and the specific isoform of PKC that interacts with $\mathrm{LTC}_{4}$ synthase are unknown. Whether $\mathrm{LTC}_{4}$ synthase is phosphorylated during cell activation has not been demonstrated. Two intriguing possibilities are that phosphorylation disrupts protein interactions and/or that it causes membrane redistribution of LTC $_{4}$ synthase.

\section{Consequences of eicosanoid signaling}

Why have cells evolved such complex mechanisms to control the initiation of signaling by $5-\mathrm{LO}$, other lipoxygenases, and COXs? Increasing evidence indicates that the initiation of lipid signaling comes at a potential cost to cells, particularly with respect to the generation of ROS and lipid hydroperoxides. In several model systems, the 5-LO enzyme contributes to the generation of ROS that activate NF-KB (62). Secondly, $\mathrm{LTA}_{4}$ has the potential to form adducts with DNA bases, suggesting that it may potentially serve as a modulator of transcription or as a mutagen (83). In the case of terminally differentiated myeloid cells, the adduction of $\mathrm{LTA}_{4}$ may function as a modulator of gene expression similar to methylation. More dire consequences may occur in conditions of chronic inflammation. Recent studies have shown that transcellular $\mathrm{LTA}_{4}$ conversion of $\mathrm{LTA}_{4}$ to $\mathrm{LTB}_{4}$ occurs in in vivo models of inflammation (84). This finding suggests that $\mathrm{LTA}_{4}$, generated by phagocytes, has the potential to form adducts in tissue DNA. In addition, the initial product of 5-LO, 5-HPETE, is a reactive hydroperoxide. The potential for the products of lipoxygenase reactions to generate cellular damage is typified by $15-\mathrm{LO}$, which has been implicated in the pathogenesis of atherosclerosis secondarily to its ability to utilize esterified phospholipids as a substrate $(85,86)$.

A second series of studies has suggested a mechanism by which the generation of PGs and electrophilic lipid hydroperoxides might couple inflammation and cancer but may also downregulate inflammation by interacting with NF-אB (87-95). Cyclopentanone PGs are generated late in the inflammatory process. PGs of the J and A series can inactivate wild-type p53 tumor-suppressor protein. This is based on the chemical reactivity of molecules that contain $\alpha, \beta$-unsaturated ketones. The J series of PGs are more potent antiproliferative molecules than the A series and are more stable, and last longer. They are derived from $\mathrm{PGD}_{2}$, and their addition to cells results in the inactivation of wild-type tumor suppressor p53. It is becoming clear that these molecules have the ability to modify multiple redox-sensitive transcription factors. The addition of $\mathrm{PGJ}_{2}$ to cells triggers a series of events that are dependent on the generation of ROS and that can be prevented by the addition of the radical quencher $\mathrm{N}$-acetyl-L-cysteine. These effects suggest that cyclopentanone PGs, 15 -deoxy- $\Delta^{12,14}-\mathrm{PGJ}_{2}$ in particular, are either a source of markedly increased ROS generation or modulators of ROS sensitivity. Recently, a mechanism has been proposed that integrates these observations. As a consequence of its unique chemical reactivity properties, $\mathrm{PGA}_{1}$ and a PGA analog can react with and covalently modify selenium-containing enzymes and proteins, including thioredoxin reductase. This impairs the reduction of redox-sensitive proteins by thioredoxin, indicating that electrophilic PGs and lipids can function as amplifiers of oxidative stress. This would include the activation of apoptosis signal-related kinase-1, which would be released during the oxidation of thioredoxin. $\Delta 12-\mathrm{PGJ}_{2}$ can also inactivate ubiquitin isopeptidase 
activity of the proteasome pathway. A series PGs antagonize p53-dependent apoptosis but not cell-cycle arrest. These effects are consistent with inhibition of thioredoxin reductase. Moos et al. $(87,90)$ have suggested that inhibition of thioredoxin reductase-thioredoxin cycling would prevent the assembly of p53 into a transcriptionally competent form, blocking apoptosis. Inhibition of thioredoxin reductase-thioredoxin cycling would disrupt ribonucleotide reductase activity, resulting in cellcycle arrest during $\mathrm{G} 1$, because ribonucleotide reductase is the rate-limiting enzyme in DNA synthesis.

The generation of lipid hydroperoxides within or near the cell nucleus must confer a benefit. One possibility is that the generation of PGs and LTs on the nuclear envelope is important for the signaling or regulation of transcription. For example, $\mathrm{LTB}_{4}$ has been suggested as an endogenous ligand for PPAR $\alpha$ (66), though the significance of this observation is unclear. An intriguing, though untested, possibility is that the generation of PGs and LTs on the nuclear envelope could provide a mechanism for altering nuclear redox tone as a result of the "controlled" lipoxygenase or COX reactions. This would regulate a series of redox-sensitive transcriptional events. The physical association of 5-LO with other proteins suggests a direct role in transcription. The role of redox signaling and oxygen-dependent transcription in regulating the inflammatory response has recently been supported by the observation that hypoxia-inducible factor $1 \alpha$ is required for an inflammatory response by myeloid cells. The potential for 5-LO to generate sufficient ROS to affect NF-KB (62) provides a direct and feasible link between 5-LO-generated redox changes and transcription.

The topology of the biosynthetic enzymes involved in PG and LT synthesis may also be an adaption to the generation of lipid hydroperoxides. The active sites of COX1 and COX2 (96), FLAP (39), and $\mathrm{LTC}_{4}$ synthase (42) (as shown in Figure 2) are all oriented toward the ER lumen, a location with high glutathione levels. Whether mPGES-1 has the same topology as these other MAPEG enzymes is unknown, but it would not be surprising if they were similarly oriented.

\section{Signaling by LTs and PGs}

Although signaling that is mediated by a combination of oxygen and lipid interaction has potentially disastrous consequences for cells, it provides one great advantage: diversity. Whereas a large portion of the genome is devoted to coding for kinases and phosphatases, the multiple signaling pathways of arachidonic acid are governed by only three classes of enzymes that initially add oxygen to the substrate. These are (a) COXs, which initiate the synthesis of PGs; (b) lipoxygenases such as 5-LO, which initiate the synthesis of LTs, 12-, 15-, and 8-LO; and (c) cytochrome P450s, which catalyze the formation of epoxyeicosatrienoic acids (EETs) or the formation of 20 -hydroxyeicosatetraenoic acid. These enzymes gen- erate products of differing biological activity by inserting oxygen at different positions in arachidonic acid. The use of enzymes of different classes to initiate oxygenation has a distinct advantage in that, because of their different mechanisms, the initial oxygenations result in molecules of different properties, limiting the next series of oxygenations, isomerizations, or reductions that can be performed. Thus, cytochrome P450 epoxygenases can generate 5,6-EET, but the biology of this molecule is completely distinct from that of $\mathrm{LTA}_{4}$, another 5,6-epoxide. Similarly, the products of COX, but not of lipoxygenases, can be converted to thromboxane and prostacyclin in subsequent reactions.

The second mechanism that generates functional diversity within any individual class of enzymes is regiospecificity for the substrate. The 5-, 12-, and 15-LOs each generate products with different potential biological function. In addition, 12- and 15-LO can utilize esterified fatty acids as substrates. This positional specificity and the ability to utilize esterified phospholipids as substrates provide a basis for the proposed role of 15 -LO in the early phases of atherosclerosis with the generation of reactive lipid aldehydes and free radicals $(85,86)$.

It was initially presumed that the presence of two COX genes was a unique property of the COX enzyme class, but it now appears to be more the rule than the exception in eicosanoid biochemistry. As described above, there are two $\mathrm{PGE}_{2}$ synthase enzymes. There are also two enzymes that catalyze the synthesis of $\mathrm{PGD}_{2}$ (one in hematopoietic cells and one in the brain), two 15-LOs, two 12-LOs, and multiple cytochrome P450 epoxygenases. Each of these variants may function differently by being coupled to different stimuli in different tissues, or by being differentially compartmentalized within cells. The advantage of this is that different pools of eicosanoids can potentially be coupled to different functions (for examples see refs. 73-76, 96). In addition, the recent discovery of a $G$ protein-coupled receptor for arachidonic acid indicates that even the lack of enzymatic oxygen can import biological information mediated by arachidonic acid (97).

As recently described by Narumiya and Fitzgerald (98), this theme is echoed by PG receptors. Eight types and subtypes of membrane prostanoid receptors are conserved in mammals from mice to humans: the PGD receptor, DP; four subtypes of the PGE receptor, EP1, EP2, EP3, and EP4; the PGF receptor, FP; the PGI receptor, IP; and the thromboxane A receptor, TP. They have different cell- and tissue-specific functions, determined by selective coupling to $G$ proteins and by the expression of splicing isoforms. Their role as inhibitory versus constrictive is determined by coupling and splicing. The theme of multiple receptors has been expanded to include the LT receptors, whose different functions have been found to be mediated by two $\mathrm{LTB}_{4}$ receptors, two cysteinyl $\mathrm{LT}$ receptors, and two $\mathrm{PGD}_{2}$ receptors. Thus, the temporal, cell-specific, and intracellular distribution of biosynthetic enzymes 
controls the generation of eicosanoids within inflammation, whereas the cellular distribution, temporal induction, and coupling of their $G$ protein-coupled receptors can diversify responses and control whether the responses are proinflammatory. $G_{s}, G_{i}$, or $G_{q}$ proteins can couple signaling by a single molecule to multiple responses in different tissues or cells, and in a given cell.

In summary, the combination of 20 carbons and four unsaturated double bonds has proved to be one of the most flexible molecular combinations yet described and has provided the stimulus for over 50 years of intense investigation. As more roles and interactions for arachidonic acid products are identified, it is clear that this molecule will remain an integral component of biomedical research for at least another 50 years.

\section{Acknowledgments}

This work was supported by NIH grants R01GM061823 (to R.J. Soberman), K01DK-59991 (to P. Christmas), and an unrestricted gift from the Jewish Communal Fund (to R.J. Soberman). The authors would like to thank Lawrence Marnett, K. Frank Austen, Robert C. Murphy, and Frank Fitzpatrick for helpful discussions.

1. Soberman, R.J. 2003. The expanding network of redox signaling: new observations, complexities, and perspectives. J. Clin. Invest. 111:571-574. doi:10.1172/JCI200318099

2. Lewis, R.A., Austen, K.F., and Soberman, R.J. 1990. Leukotrienes and other products of the 5-lipoxygenase pathway. Biochemistry and relation to pathobiology in human diseases. N. Engl. J. Med. 323:645-655.

3. Samuelsson, B., et al. 1987. Leukotrienes and lipoxins: structures, biosynthesis, and biological effects. Science. 237:1171-1177.

4. Weller, P.F., et al. 1983. Generation and metabolism of 5-lipoxygenase pathway leukotrienes by human eosinophils: predominant production of leukotriene C. Proc. Natl. Acad. Sci. U. S. A. 80:7626-7630.

5. Owen, W.F., Jr., et al. 1987. Synthesis and release of leukotriene $\mathrm{C}_{4}$, by human eosinophils. J. Immunol. 138:532-538.

6. Tripp, C.S., Mahoney, M., and Needleman, P. 1985. Calcium ionophore enables soluble agonists to stimulate macrophage 5-lipoxygenase. J. Biol. Chem. 260:5895-5898.

7. Goldyne, M.E., Burrish, G.F., Poubelle, P., and Borgeat, P. 1984. Arachidonic acid metabolism among human mononuclear leukocytes. Lipoxygenase-related pathways. J. Biol. Chem. 259:8815-8819.

8. Lynch, K.R., et al. 1999. Characterization of the human cysteinyl leukotriene CysLT1 receptor. Nature. 399:78-93.

9. Heise, C.E., et al. 2002. Characterization of the human cysteinyl leukotriene 2 receptor. J. Biol. Chem. 275:30531-30536.

10. Griffin, M., et al. 1983. Effects of leukotriene D on the airways in asthma. N. Engl. J. Med. 308:436-439.

11. Weiss, J.W., et al. 1982. Bronchoconstrictor effects of leukotriene C in humans. Science. 216:196-198.

12. Taylor, G.W., et al. 1989. Urinary $\mathrm{LTE}_{4}$ after antigen challenge in acute asthma and allergic rhinitis. Lancet. 1:584-588.

13. Manning, P.J., et al. 1990. Inhibition of excercised induced bronchonstriction by MK-571, a potent leukotriene $\mathrm{D}_{4}$-receptor antagonist. N. Engl. J. Med. 323:1736-1769.

14. Finnerty, J.P., Wood-Baker, R., Thompson, H., and Holgate, S.T. 1993. Role of leukotrienes in exercise induced asthma. Inhibitory effect of ICI 204,219, a potent $\mathrm{LTD}_{4}$ receptor antagonist. Am. Rev. Respir. Dis. 145:746-749.

15. Taylor, I.K., O'Shaughnessy, K.M., Fuller, R.W., and Dollery, C.T. 1991. Effect of cysteinyl-leukotriene receptor antagonist ICI 204.219 on allergen induced bronchoconstriction and airway hyperreactivity in atopic subjects. Lancet. 337:690-694.

16. Reiss, T.F., et al. 1996. Effects of monteleukast (MK-0476), a new potent cysteinyl leukotriene $\left(\mathrm{LTD}_{4}\right)$ receptor antagonist, in patients with chronic asthma. J. Allergy Clin. Immunol. 98:528-534.

17. Israel, E., Cohn, J., Dube, L., and Drazen, J.M. 1996. Effect of treatment with zileuton, a 5-lipoxygenase inhibitor, in patients with asthma. A randomized controlled trial. Zileuton Clinical Trial Group. JAMA. 275:931-936.
18. Bonnin, A.J., et al. 2002. Mild asthma. N. Engl. J. Med. 346:1335-1336.

19. Kay, A.B. 2001. Advances in immunology: allergy and allergic diseases. First of two parts. N. Engl. J. Med. 344:30-37.

20. Busse, W.W., and Lemanske, R.F. 2001. Advances in immunology: asthma. N. Engl. J. Med. 344:350-362.

21. Israel, E., et al. 1993. The effect of inhibition on 5-lipoxygenase by zileuton in mild to moderate asthma. Ann. Intern. Med. 119:1059-1066.

22. Naureckas, E.T., and Solway, J. 2001. Mild asthma. N. Engl. J. Med. 345:1257-1262.

23. Drazen, J.M., Israel, E., and O’Byrne, P.M. 1999. Drug therapy. Treatment of asthma with drugs modifying the leukotriene pathway. N. Engl. J. Med. 340:197-206.

24. Sousa, A.R., et al. 2002. Leukotriene-receptor expression on nasal mucosa in aspririn-sensitive rhinosinusitis. N. Engl. J. Med. 347:1524-1526.

25. Honig, S.M., et al. 2003. FTY720 stimulates multidrug transporter- and cysteinyl leukotriene-dependent $\mathrm{T}$ cell chemotaxis to lymph nodes. J. Clin. Invest. 111:627-637. doi:10.1172/JCI200316200.

26. Kanaoka, Y., et al. 2001. Attenuated zymosan-induced peritoneal vascular permeability and IgE-dependent passive cutaneous anaphylaxis in mice lacking leukotriene $\mathrm{C}_{4}$ synthase. J. Biol. Chem. 276:22608-22613.

27. Hui, Y., et al. 2001. The murine cysteinyl leukotriene 2 (CysLT2) receptor. cDNA and genomic cloning, alternative splicing, and in vitro characterization. J. Biol. Chem. 276:47489-47495.

28. Maekawa, A., Kanaoka, Y., Lam, B.K., and Austen, K.F. 2001. Identification in mice of two isoforms of the cysteinyl leukotriene 1 receptor that result from alternative splicing. Proc. Natl. Acad. Sci. U. S. A. 98:2256-2261.

29. Glover, S., et al. 1995. Translocation of the $85-\mathrm{kDa}$ phospholipase $\mathrm{A}_{2}$ from cytosol to the nuclear envelope in rat basophilic leukemia cells stimulated with calcium ionophore or IgE/antigen. J. Biol. Chem. 270:15399-15407.

30. Kargman, S., Vickers, P.J., and Evans, J.F. 1992. A23187-induced translocation of 5-lipoxygenase in osteosarcoma cells. J. Cell Biol. 119:1701-1709.

31. Rouzer, C.A., and Kargman, S. 1988. Translocation of 5-lipoxygenase to the membrane in human leukocytes challenged with ionophore A23187. J. Biol. Chem. 263:10980-10988.

32. Woods, J.W., et al. 1993. 5-lipoxygenase and 5-lipoxygenase-activating protein are localized in the nuclear envelope of activated human leukocytes. J. Exp. Med. 178:1935-1946.

33. Rouzer, C.A., Matsumoto, T., and Samuelsson, B. 1986. Single protein from human leukocytes possesses 5-lipoxygenase and leukotriene $\mathrm{A}_{4}$ synthase activities. Proc. Natl. Acad. Sci. U. S. A. 83:857-861.

34. Miller, D.K., et al. 1990. Identification and isolation of a membrane protein necessary for leukotriene production. Nature. 343:278-281.

35. Dixon, R.A., et al. 1990 . Requirement of a 5-lipoxygenase-activating protein for leukotriene synthesis. Nature. 343:282-284.

36. Mancini, J.A., et al. 1993. 5-Lipoxygenase-activating protein is an arachidonic acid binding protein. FEBS Lett. 318:277-281.

37. Radmark, O., Shimizu, T., Jornvall, H., and Samuelsson, B. 1988. Leukotriene $\mathrm{A}_{4}$, hydrolase in human leukocytes. Purification and properties. J. Biol. Chem. 259:12339-12345.

38. Lam, B.K., Gagnon, L., Austen, K.F., and Soberman, R.J. 1990. The mechanism of leukotriene $\mathrm{B}_{4}$ export from human polymorphonuclear leukocytes. J. Biol. Chem. 265:13438-13441.

39. Yokomizo, T., et al. 1997. A G-protein-coupled receptor for leukotriene $\mathrm{B}_{4}$ that mediates chemotaxis. Nature. 387:620-624.

40. Yokomizo, T., Kato, K., Terawaki, K., Izumi, T., and Shimizu, T. 2000. A second leukotriene $B_{4}$ receptor, BLT2: a new therapeutic target in inflammation and immunological disorders. J. Exp. Med. 192:421-432.

41. Penrose, J.F., et al. 1992. Purification of human leukotriene $\mathrm{C}_{4}$ synthase. Proc. Natl. Acad. Sci. U. S. A. 89:11603-11606.

42. Lam, B.K., Penrose, J.F., Freeman, G.J., and Austen, K.F. 1994. Expression cloning of a cDNA for human leukotriene $\mathrm{C}_{4}$ synthase, an integral membrane protein conjugating reduced glutathione to leukotriene $\mathrm{A}_{4}$. Proc. Natl. Acad. Sci. U. S. A. 91:7663-7667.

43. Welsch, D.J., et al. 1994. Molecular cloning and expression of human leukotriene-C 4 synthase. Proc. Natl. Acad. Sci. U. S. A. 91:9745-9749.

44. Christmas, P., et al. 2002. Membrane localization and topology of leukotriene $\mathrm{C}_{4}$ synthase. J. Biol. Chem. 277:28902-28908.

45. Lam, B.K., Owen, W.F., Jr., Austen, K.F., and Soberman, R.J. 1989. The identification of a distinct export step following the biosynthesis of leukotriene $\mathrm{C}_{4}$ by human eosinophils. J. Biol. Chem. 264:12885-12889.

46. Jedlitschky, G., Buchholz, U., and Keppler, D. 1994. Characterization of the ATP-dependent leukotriene $\mathrm{C}_{4}$ export carrier in mastocytoma cells. J. Biochem. 220:599-563.

47. Loe, D.W., Almquist, K.C., Deeley, R.G., and Cole, S.P.C. 1996. Multidrug resistance protein (MRP)-mediated transport of leukotriene $\mathrm{C}_{4}$ and chemotherapeutic agents in membrane vesicles. J. Biol. Chem. 271:9675-9683

48. Wijnholds, J., et al. 1997. Increased sensitivity to anticancer drugs and 
decreased inflammatory response in mice lacking the multidrug resistance-associated protein. Nat. Med. 3:1275-1279.

49. Robbiani, D.F., et al. 2000. The leukotriene C(4) transporter MRP1 regulates CCL19 (MIP-3beta, ELC)-dependent mobilization of dendritic cells to lymph nodes. Cell. 103:757-768.

50. Clark, J.D., et al. 1991. A novel arachidonic acid-selective cytosolic PLA contains a $\mathrm{Ca}(2+)$-dependent translocation domain with homology to PKC and GAP. Cell. 65:1043-1051.

51. Nalekski, E.A., et al. 1994. Delineation of two functionally distinct domains of cytosolic phospholipase $\mathrm{A}_{2}$, a regulatory $\mathrm{Ca}^{2+}$-dependent lipid binding domain and a $\mathrm{Ca}^{2+}$-independent catalytic domain. J. Biol. Chem. 269:18239-18249.

52. Lin, L.L., et al. 1993. Cytoplasmic PLA 2 is activated by MAP kinase. Cell. 72:269-278.

53. Borsh-Haubold, A.G., et al. 1998. Identification of the phosphorylation sites on cytosolic phospholipase $\mathrm{A}_{2}$ in agonist-stimulated human platelets and HeLa cells. J. Biol. Chem. 273:4449-4458.

54. de Carvalho, M.G.S., et al. 1996. Identification of the phosphorylation sites of the $85-\mathrm{kDa}$ cytosolic phospholipsae $\mathrm{A}_{2}$ expressed in insect cells and present in human monocytes. J. Biol. Chem. 271:6987-6997.

55. Gijón, M.A., et al. 1999. Role of phosphorylation sites and the $\mathrm{C} 2$ domain in regulation of cytosolic phospholipase $A_{2}$. J. Cell Biol. 145:1219-1232.

56. Bonventre, J.V., et al. 1997. Reduced fertility and postischaemic brain injury in mice deficient in cytosolic phospholipase $A_{2}$. Nature. 390:622-625.

57. Evans, J.H., et al. 2001. Intracellular calcium signals regulating cytosolic phospholipase $\mathrm{A}_{2}$ translocation to internal membranes. J. Biol. Chem. 276:30150-30160.

58. Lepley, R.A., Muskardin, D., and Fitzpatrick, F.A. 1996. Tyrosine kinase activity modulates catalysis and translocation of cellular 5-lipoxygenase. J. Biol. Chem. 271:6179-6184.

59. Lepley, R.A., and Fitzpatrick, F.A. 1996. Inhibition of MAP kinase kinase blocks activation and redistribution of 5-lipoxygenase in HL-60 cells. Arch. Biochem. Biophys. 331:141-144.

60. Lepley, R.A., and Fitzpatrick, F.A. 1994. 5-Lipoxygenase contains a functional Src homology 3-binding motif that interacts with the Src homology 3 domain of Grb2 and cytoskeletal proteins. J. Biol. Chem. 269:24163-24168

61. Werz, O., et al. 2000. 5-Lipoxygenase is phosphorylated by p38 kinasedependent MAPKAP kinases. Proc. Natl. Acad. Sci. U. S. A. 97:5261-5266.

62. Lepley, R.A., and Fitzpatrick, F.A. 1998. 5-Lipoxygenase compartmentalization in granulocytes is modulated by an internal nuclear localization signal and NF-KB complex formation. Arch. Biochem. Biophys. 356:71-76

63. Bonizzi, B., et al. 1999. Reactive oxygen intermediate-dependent NF-кB activation by interleukin-1 requires 5-lipoxygenase or NADPH oxidase activity. Mol. Cell. Biol. 19:1950-1960.

64. Kulkani, S., et al. 2002. Molecular basis of the specific subcellular localization of the C2-like domain of 5-lipoxygenase. J. Biol. Chem. 277:3568-3575.

65. Brock, T.G., Maydanski, E., McNish, R.W., and Peters-Golden, M. 2001 Co-localization of leukotriene $\mathrm{A}_{4}$ hydrolase with 5-lipoxygenase in nuclei of alveolar macrophages and rat basophilic leukemia cells but not neutrophils. J. Biol. Chem. 276:35071-35077.

66. Devchand, P.R., et al. 1996. The PPARalpha-leukotriene $B_{4}$ pathway to inflammation control. Nature. 384:39-43.

67. Woods, J.W., et al. 1995. 5-Lipoxygenase is located in the euchromatin of the nucleus in resting human alveolar macrophages and translocates to the nuclear envelope upon cell activation. J. Clin. Invest. 95:2035-2046.

68. Chen, X.-S., et al. 1995. cDNA cloning, expression, mutagenesis, intracellular localization, and gene chromosomal assignment of mouse 5-lipoxygenase. J. Biol. Chem. 270:17993-17999.

69. Chen, X.-S., Zhang, Y.-Y., and Funk, C.D. 1998. Determinants of 5-lipoxygenase nuclear localization using green fluorescent protein/ 5-lipoxygenase fusion proteins. J. Biol. Chem. 273:31237-31244.

70. Christmas, P., Fox, J.W., Ursino, S.R., and Soberman, R.J. 1999. Differential localization of 5- and 15-lipoxygenases to the nuclear envelope in RAW macrophages. J. Biol. Chem. 274:25594-25598.

71. Lam, B.K., et al. 1997. Site-directed mutagenesis of human leukotriene $\mathrm{C}_{4}$ synthase. J. Biol. Chem. 272:13923-13928.

72. Jakobsson, P.-J., Mancini, J.A., and Ford-Hutchinson, A.W. 1997. Identification and characterization of a novel human microsomal glutathione $S$-transferase with leukotriene $\mathrm{C}_{4}$ synthase activity and significant sequence identity to 5 -lipoxygenase-activating protein and leukotriene $\mathrm{C}_{4}$ synthase. J. Biol. Chem. 271:22203-22210.

73. Jakobsson, P.-J., et al. 1999. Identification of human prostaglandin E synthase: a microsomal, glutathione-dependent, inducible enzyme, constituting a potential novel drug target. Proc. Natl. Acad. Sci. U. S. A. 96:7220-7225.
74. Han, R., Tsui, S., and Smith, T.J. 2002. Up-regulation of prostaglandin $\mathrm{E}_{2}$ synthesis by interleukin-1 $\beta$ in human orbital fibroblasts involves coordinate induction of prostaglandin-endoperoxide $\mathrm{H}$ synthase- 2 and glutathione-dependent prostaglandin $\mathrm{E}_{2}$ synthase expression. J. Biol. Chem. 277:16355-16364.

75. Murakami, M., et al. 2000. Regulation of prostaglandin $\mathrm{E}_{2}$ biosynthesis by inducible membrane-associated prostaglandin $\mathrm{E}_{2}$ synthase that acts in concert with cyclooxygenase-2. J. Biol. Chem. 275:32783-32792.

76. Tanioka, T., et al. 2000. Molecular identification of cytosolic prostaglandin $\mathrm{E}_{2}$ synthase that is functionally coupled with cyclooxygenase- 1 in immediate prostaglandin $\mathrm{E}_{2}$ biosynthesis. J. Biol. Chem. 275:32775-32782.

77. Smith, W.L., Garavito, R.M., and DeWitt, D.L. 1996. Prostaglandin endoperoxide $\mathrm{H}$ synthases (cyclooxygenases)-1 and -2. J. Biol. Chem. 271:33157-33160.

78. Rouzer, C.A., et al. 1990. MK886, a potent and specific leukotriene biosynthesis inhibitor blocks and reverses the membrane association of 5-lipoxygenase in ionophore-challenged leukocytes. J. Biol. Chem. 265:1436-1442

79. Gupta, N., Nicholson, D.W., and Ford-Hutchinson, A.W. 1999. Demonstration of cell-specific phosphorylation of $\mathrm{LTC}_{4}$ synthase. FEBS Lett. 449:66-70.

80. Ali, A., Nicholson, D.W., and Ford-Hutchinson, A.W. 1995. Characterization of human $\mathrm{LTC}_{4}$ synthase. Adv. Prostaglandin Thromboxane Leukot. Res. 23:171-173.

81. Ali, A., Ford-Hutchinson, A.W., and Nicholson, D.W. 1994. Activation of protein kinase $C$ down-regulates leukotriene $\mathrm{C}_{4}$ synthase activity and attenuates cysteinyl leukotriene production in an eosinophilic substrain of HL-60 cells. J. Immunol. 153:776-788.

82. Kargman, S., et al. 1994. Protein kinase C-dependent regulation of sulfidopeptide leukotriene biosynthesis and leukotriene $\mathrm{C}_{4}$ synthase in neutrophilic HL-60 cells. Mol. Pharmacol. 45:1043-1049.

83. Reiber, D.C., and Murphy, R.C. 2000. Covalent binding of LTA(4) to nucleosides and nucleotides. Arch. Biochem. Biophys. 379:119-126.

84. Fabre, J.-E., et al. 2002. Transcellular biosynthesis contributes to the production of leukotrienes during inflammatory responses in vivo. J. Clin. Invest. 109:1373-1380. doi:10.1172/JCI200214869.

85. Schewe, T. 2002. 15-Lipoxygenase-1: a prooxidant enzyme. Biol. Chem. 383:365-374.

86. Cyrus, T., et al. 1999. Disruption of the 12/15-lipoxygenase gene diminishes atherosclerosis in apo E-deficient mice. J. Clin. Invest. 103:1597-1604

87. Moos, P.J., et al. 2003. Electrophilic prostaglandins and lipid aldehydes repress redox-sensitive transcription factors $\mathrm{p} 53$ and hypoxia-inducible factor by impairing the selenoprotein thioredoxin reductase. J. Biol. Chem. 278:745-750.

88. Mullally, J.E., Moos, P.J., Edes, K., and Fitzpatrick, F.A. 2001. Cyclopentenone prostaglandins of the J series inhibit the ubiquitin isopeptidase activity of the proteasome pathway. J. Biol. Chem. 276:30366-30373.

89. Kondo, T., et al. 2002. 15-Deoxy-12,14-prostaglandin J2: the endogenous electrophile that induces neuronal apoptosis. Proc. Natl. Acad. Sci. U. S. A. 99:7367-7372

90. Moos, P.J., Edes, K., and Fitzpatrick, F.A. 2000. Inactivation of wild-type p53 tumor suppressor by electrophilic prostaglandins. Proc. Natl. Acad. Sci. U. S. A. 97:9215-9220.

91. Cerunda-Morollon, E., Pineda-Molina, E., Canada, F.J., and Perez-Sula, D. 2001. 15-deoxy-delta 12, 14-prostagladin $\mathrm{J}_{2}$ NF-kB-DNA binding through covalent modification of the p50 subunit. J. Biol. Chem. 276:35530-35536.

92. Straus, D.S., et al. 2000. 15-Deoxy-12,14-prostaglandin J2 inhibits multiple steps in the NF-KB signaling pathway. Proc. Natl. Acad. Sci. U. S. A. 97:4844-4849.

93. Petrova, T.V., Akama, K.T., and Van Eldik, L.J. 1999. Cyclopentenone prostaglandins suppress activation of microglia: down-regulation of inducible nitric-oxide synthase by 15-deoxy-12,14-prostaglandin $\mathrm{J}_{2}$. Proc. Natl. Acad. Sci. U. S. A. 96:4668-4673.

94. Khan, S.H., and Sorof, S. 1990. Preferential binding of growth inhibitory prostaglandins by the target protein of a carcinogen. Proc. Natl. Acad. Sci.U. S. A. 87:9401-9405.

95. Rossi, A., et al. 2000. Anti-inflammatory cyclopentenone prostaglandins are direct inhibitors of IкB kinase. Nature. 403:103-118.

96. Smith, W.L., and Langenbach, R. 2001. Why there are two cyclooxygenase isozymes. J. Clin. Invest. 107:1491-1495.

97. Itoh, Y., et al. 1993. Free fatty acids regulate insulin secretion from pancreatic beta cells through GPR40. Nature. 244:173-176. doi:10.1038/nature01478.

98. Narumiya, S., and Fitzgerald, G.A. 2001. Genetic and pharmacological analysis of prostanoid receptor function. J. Clin. Invest. 108:25-30. doi:10.1172/JCI200113455. 